\title{
KẾT QUẢ SỚM PHẪU THUẬT KẾT HỢP CAN THIỆP ĐỒNG THİ ĐIỀU TRI BỆNH THIẾU MÁU CHI DƯỚI MẠN TÍNH TẠI BỆNH VIỆN HŨ̉U NGH!̣ VIỆT ĐỨC GIAI ĐOẠN 2015- 2019
}

\author{
Kim Công Thương*, Phùng Duy Hồng Son**, Đoàn Quốc Hung**
}

\section{TÓM TẮT}

Bệnh nhân $(\mathrm{BN})$ thiếu máu chi dưới mạn tínhđiều trị bằng phương pháp Hybrid từ 1/20153/2019 tại Khoa phẫu thuật Tim mạch Bệnh viện HN Việt Đức. Các kỹ thuật hybrid đã thực hiện: stent động mạch (ĐM) chậu bắc cầu ĐM đùikhoeo10 BN (19,2\%); stent ĐM chậu bắc cầu ĐM đùi-đùi24 $\mathrm{BN}(46,1 \%)$; nong $\mathrm{DM}$ đùi nông bắc cầu $Đ M$ đùi-đùi3 $\mathrm{BN}(5,7 \%)$; stent $\mathrm{ĐM}$ chậu bóc nội mạc ĐM đùi9 BN (17,3\%); nong ĐM chậu bóc nội mạc ĐM đùi1 $\mathrm{BN}(1,9 \%)$; stent $Đ M$ chậu bắc cầu ĐM chậu-khoeo1 BN (1,9\%); nong ĐM chày, mác bắc cầu ĐM chậu-khoeo4 $\mathrm{BN}(7,69 \%)$. Các tai biến đều kiểm soát được hoàn toàn trong quá trình điều trị.Hiệu quả cải thiện tưới máu chi cao: $\mathrm{ABI}$ tăng rõ rệt từ $0,36 \pm 0,23$ lên $0,65 \pm 0,25$ (p $<0,05)$. Chi được bảo tồn chiếm $98,03 \%$.

Tù̀ khóa: Phẫu thuật kết hợp can thiệp nội mạch đồng thì, bệnh thiếu máu chi dưới mạn, bệnh mạch máu ngoại biên.

\section{ABSTRACT \\ EARLY RESULTS OF HYBRID PROCEDURES FOR TREATMENT OF CHRONIC LOWER LIMB ISCHEMIAAT VIET DUC NIVERSITYHOSPITAL DURING PERIOD 2015-2019}

Objective: To evaluate the early results of hybrid procedures for treatment of chronic lower limb ischemia. Subject: Alls patients with chronic lower limb ischemia treated by hybrid from January 2015 to March 2019 in Department of Cardiovascular and thoralic surgery, Viet Duc university Hospital. Methods: Descriptive retrospective study. Results: There are 52 patients including in study. Hybrid procedures were performed: iliac artery stent and femoral-popliteal bypass 10patients $(19,2 \%)$; iliac artery stent and femoral-femoral bypass 24(46,1\%); balloon dilatation of femoral artery and femoral-femoral bypass 3 (5,7\%); iliac artery stent and endoarterectomy of femoral artery 9(17,3\%); balloon dilatation of iliac artery and endoarterectomy of femoral artery $1(1,9 \%)$; iliac artery stent and iliac-popliteal bypass $1(1,9 \%)$; balloon dilatation of tibial, peroneal artery and iliac-popliteal bypass 4(7,69\%). All complications can be completely controlled during treatment period. High efficiency of revascularization: ABI increased significantly from $0,36 \pm 0,23$ to $0,65 \pm 0,25 \quad(p<0.05)$. Lower limb preserved 98,03\%. Conclusions: Hybrid procedures were safety and significantly improved clinical symptoms and paraclinical results in patients with chornic lower limb ischemia in sort term folow up.

Keywords: surgery combined intravascular interventions, hybrid procedures, chronic lower limb ischemia, peripheral vascular disease.

\section{I. ĐẶT VẤN ĐỀ}

Thiếu máu chi dưới mạn tính (TMCDMT) là tình trạng một phần hay toàn bộ chi dưới không được cung cấp đầy đủ máu đáp ứng các hoạt động sinh lý, gây ra do hẹp, tắc các ĐM nuôi

* BV Đa khoa Vĩnh Phúc

** BV HN Việt Đúc, Truò̀ng ĐH Y Hà Nội

Người chịu trách nhiệm khoa họ: PGS.TS.Đoàn Quốc Hung

Ngày nhận bài: 01/05/2019 - Ngày Cho Phép Đăng: 15/05/2019

Phản Biện Khoa học: PGS.TS. Đặng Ngọc Hùng

GS.TS. Lê Ngọc Thành 
chi [1]. Những bệnh nhân có bệnh mạch máu phức tạp, tuổi cao, nhiều vị trí tổn thương việc áp dụng các phương pháp kinh điển như phẫu thuật đơn thuần hoặc can thiệp đơn thuần sẽ không mang lại hiệu quả tốt do phẫu thuật tại nhiều vị trí cùng một lúc trên bệnh nhân già yếu sẽ ảnh hưởng nặng nề đến sức khỏe bệnh nhân, việc can thiệp mạch máu trên nhiều vị trí cùng một lúc không phải lúc nào cũng thực hiện được. Xu hướng trên thế giới hiện nay là áp dụng phối hợp phẫu thuật và can thiệp trên một bệnh nhân trong một thì nhằm làm giảm độ khó của phẫu thuật can thiệp, giảm chi phí y tế và giảm tác động có hại trên sức khỏe bệnh nhân [2].

Tại bệnh viện HNViệt Đức đã có nhiều trường hợp thiếu máu mạn tính chi dưới được điều trị bằng phương pháp phẫu thuật kết hợp can thiệp đồng thì. Vì vậy chúng tôi thực hiện đề tài này nhằm mục tiêu đánh giá kết quả sớm điều trị bệnh thiếu máu chi dưới mạn tính bằng phương pháp phẫu thuật kết hợp can thiệp đồng thì (hybrid) tại Bệnh viện hữu nghị Việt Đức giai đoạn 2015-2019.

\section{II. ĐỐI TƯợNG VÀ PHƯƠNG PHÁP NGHIÊN CÚU}

Nghiên cứu mô tả, hồi cứu các $\mathrm{BN}$ thiếu máu chi dưới mạn tính được điều trịhybrid từ 1/2015-3/2019 tại Khoa phẫu thuật Tim mạch Bệnh viện Việt Đức. Bệnh nhân được chẩn đoán xác định bệnh TMCDMT dựa vào lâm sàng, siêu âm, chụp động mạch, MSCT. Chỉ định Hybrid khi bệnh khó xử lí bằng phẫu thuật hay can thiệp đơn thuần, nhiều vị trí tổn thương trên, được phân loại TASC II loại $\mathrm{C}$ và $\mathrm{D}$ hoặc giai đoạn III, IV theo phân loại Leriche-Fontaine.Thông tin bệnh án gồm hành chính, lâm sàng, cận lâm sàng được ghi chép đầy đủ. Hybrid được tiến hành tại phòng hybrid, Khoa Phẫu thuật Tim mạch Bệnh viện Việt Đức. Đánh giá các chỉ tiêu nghiên cứu trước, trong và sau mổ-can thiệp, phân tích kết quả sớm, so sánh đối chiếu với các tác giả khác.

\section{KẾT QUẢ NGHIÊN CỨU}

Trong thời gian từ $1 / 2015$ tới $3 / 2019$ có 52 $\mathrm{BN}$ đủ tiêu chuẩn nghiên cứu và 58 chi can thiệp, gồm 5 nữ và 47 nam, tuổi thấp nhất là 59 , tuổi cao nhất là 90 .

\section{1.Đặc điểm lâm sàng $\mathrm{BN}$ trước hybrid được trình bày ở bảng 1 .}

Bảng 3.1: Đặc điểm dịch tễ họcbệnh nhân khi vào viện $(N=52)$

\begin{tabular}{|c|c|c|c|}
\hline \multicolumn{2}{|c|}{ Đặc điểm lâm sàng } & \multicolumn{2}{|c|}{ Tỉ lệ } \\
\hline \multirow{2}{*}{ Giới tính } & Nam & 47 & $90,3 \%$ \\
\hline & Nữ & 5 & $9,7 \%$ \\
\hline Hút thuốc lá/ thuốc lào & & 45 & $86,5 \%$ \\
\hline Đái tháo đường & & 11 & $21,2 \%$ \\
\hline Tăng huyết áp & & 28 & $53,8 \%$ \\
\hline Rối loạn chuyển hóa mỡ & & 1 & $1,9 \%$ \\
\hline Bệnh gút & & 3 & $5,7 \%$ \\
\hline Bệnh mạch vành & & 3 & $5,7 \%$ \\
\hline Bệnh TBMMN & & 9 & $17,3 \%$ \\
\hline Tiền sử cắt cụt & & 9 & $17,3 \%$ \\
\hline
\end{tabular}




\subsection{Các kỹ thuật mổ-can thiệp đã áp dụng}

Bảng 3.2: Các kỹ thuật hybrid đã thục hiện $(N=52)$

\begin{tabular}{|l|c|}
\hline \multicolumn{1}{|c|}{ Tên kỹ thuật hybrid } & Tỉ lệ (\%) \\
\hline Stent ĐM chậu; bắc cầu ĐM đùi-ĐM khoeo & $10(19,2 \%)$ \\
\hline Stent ĐM chậu; bắc cầu ĐM đùi-ĐM đùi & $24(46,1 \%)$ \\
\hline Nong ĐM đùi nông; bắc cầu ĐM đùi-ĐM đùi & $3(5,7 \%)$ \\
\hline Stent ĐM chậu; bóc nội mạc ĐM đùi & $9(17,3 \%)$ \\
\hline Nong ĐM chậu; bóc nội mạc ĐM đùi & $1(1,9 \%)$ \\
\hline Stent ĐM chậu; bắc cầu ĐM chậu-ĐM khoeo & $1(1,9 \%)$ \\
\hline Nong ĐM chày-mác, bắc cầu ĐM chậu-ĐM khoeo & $4(7,69 \%)$ \\
\hline
\end{tabular}

\subsection{Kết quả sau Hybrid}

Bảng 3.3: Thay đổi triệu chứng lâm sàng sau Hybrid

(Tổng số chi $\mathrm{n}=58$, được tính bằng tổng số chi thiếu máu giai đoạn III và IV)

\begin{tabular}{|l|l|c|c|}
\hline \multicolumn{1}{|c|}{ Giai đoạn } & \multicolumn{1}{|c|}{ Thay đổi } & n & Tỷ lệ \% \\
\hline \multirow{3}{*}{ Giai đoạn III } & Đau không thay đổi & 0 & 0 \\
\cline { 2 - 4 } & Giảm đau & 3 & 10,0 \\
\cline { 2 - 4 } & Hết đau & 27 & 90,0 \\
\hline \multirow{2}{*}{ Giai đoạn IV } & Loét, hoại tử tiến triển tốt & 18 & 64,28 \\
\cline { 2 - 4 } & Loét, hoại tử không liền/ nặng hơn & 10 & 35,72 \\
\hline
\end{tabular}

Kiểm tra trên siêu âm chỉ có $1 \mathrm{BN}$ tắc cầu nối ĐM đùi-ĐM khoeo trái bằng mạch nhân tạo sau Hybrid (đặt stent ĐM chậu 2 bên, bóc nội mạc ĐM đùi chung 2 bên, bắc cầu đùi khoeo T), chiếm tỷ lệ $1,9 \%$. BN này được phẫu thuật lấy huyết khối mạch nhân tạo, kiểm tra lại không phát hiện hẹp hay tắc cầu nối (BN số 1).

Bảng 3.4: Thay đổi chỉ số cổ chân-cánh tay(ABI) sau điều trị.

\begin{tabular}{|c|c|c|c|c|}
\hline \multicolumn{2}{|r|}{ Thông số } & $\mathbf{N}$ & ABI & $\mathbf{F}$ \\
\hline \multirow{2}{*}{ Chân P } & Trước điều trị & \multirow{2}{*}{48} & $0,35 \pm 0,19$ & \multirow{2}{*}{$<0,05$} \\
\hline & Sau điều trị & & $0,65 \pm 0,26$ & \\
\hline \multirow{2}{*}{ Chân T } & Trước điều trị & \multirow{2}{*}{44} & $0,39 \pm 0,28$ & \multirow{2}{*}{$<0,05$} \\
\hline & Sau điều trị & & $0,66 \pm 0,25$ & \\
\hline \multirow{2}{*}{ Hai chân } & Trước điều trị & \multirow{2}{*}{92} & $0,36 \pm 0,23$ & \multirow{2}{*}{$<0,05$} \\
\hline & Sau điều trị & & $0,65 \pm 0,25$ & \\
\hline
\end{tabular}

Thời gian nằm viện trung bình (tính từ lúc vào viện tới khi ra viện) là $16,42 \pm 7,33$ ngày, dao động từ 6 ngày tới 41 ngày.
Thời gian nằm viện sau Hybrid trung bình là $11,96 \pm 5,78$, dao động từ 3 ngày tới 31 ngày. 
Sau hybridchi thiếu máu giai đoạn III: tỷ lệ $\mathrm{BN}$ giảm đau và hết đau là $100 \%$. Với $\mathrm{BN}$ thiếu máu giai đoạn IV, Có $2 \mathrm{BN}$ nhiễm trùng mỏm cụt và $1 \mathrm{BN}$ có hoại tử khô cả bàn chân trước điều trị nên không có khả năng bảo tồn chi. $6 \mathrm{BN}$ đau còn lại có triệu chứng đau buốt không thay đổi tại vị trí hoại tử ngón và được xử trí cắt cụt ngón chân hoại tử. Tất cả các $\mathrm{BN}$ này đều hết đau sau cắt cụt và mỏm cụt liền tốt trong thời gian điều trị.

\subsection{Biến chứng sau can thiệp Hybrid}

Bảng 3.5: Các biến chứng ghi nhận được sau Hybrid $(n=5)$

\begin{tabular}{|l|c|c|}
\hline Tên biến chứng & Số lượng & Tỷ lệ \% \\
\hline Tắc cầu nối (cầu đùi khoeo T) & 1 & 1,9 \\
\hline Nhiễm trùng mỏm cụt bàn chân & 1 & 1,9 \\
\hline Nhiễm trùng mỏm cụt đùi & 1 & 1,9 \\
\hline Xuất huyết tiêu hóa điều trị bảo tồn & 1 & 1,9 \\
\hline Tình trạng nhiềm trùng phải điều trị & 1 & 1,9 \\
\hline
\end{tabular}

Tình trạng cắt cụt và bảo tồn chi sau Hybridđược trình bày ở bảng 6 .

Bảng 3.6: Cắt cụt sau Hybrid $(n=9)$

\begin{tabular}{|l|l|c|c|}
\hline \multicolumn{2}{|l|}{ Loại và vị trí cắt cụt } & Số lượng & Tỷ lệ (\%) \\
\hline \multirow{2}{*}{ Cắt cụt lớn của chi } & Đùi (1/3 dưới) & 1 & 1,9 \\
\cline { 2 - 4 } & Cắng chân (1/3 dưới)* & 2 & 3,8 \\
\hline \multirow{3}{*}{ Cắt cụt nhỏ của chi } & Chopart & 1 & 1,9 \\
\cline { 2 - 4 } & Lisfranc & 1 & 1,9 \\
\cline { 2 - 4 } & Ngón chân & 4 & 7,6 \\
\hline
\end{tabular}

* Áp dụng cho: 1 BN có hoại tử khô cả bàn chân trước Hybrid và 1 BN có nhiễm trùng mỏm cụt bàn chân sau cắt cụt bàn chân tại bệnh viện tỉnh.

\subsection{Kết quả sau điều trị 1 tháng}

Có $46(88,0 \%)$ BN kiểm tra lại sau 1 tháng và 92 chi được kiểm tra, tất cả các $\mathrm{BN}$ đều có giai đoạn thiếu máu trở về giai đoạn I và II.

Thiếu máu chân $P(n=48)$

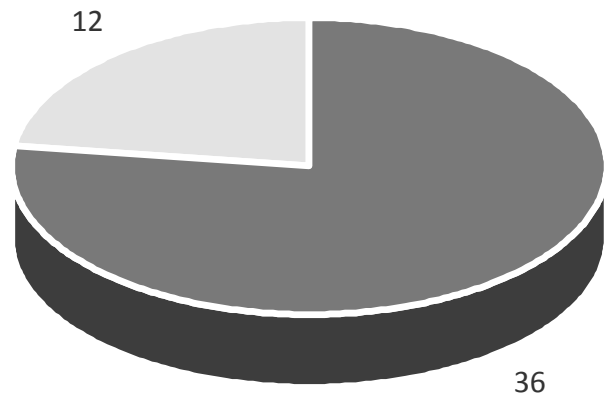

- Giai đoạn I Giai đoạn II

\section{Thiếu máu chân T ( $n=44)$}

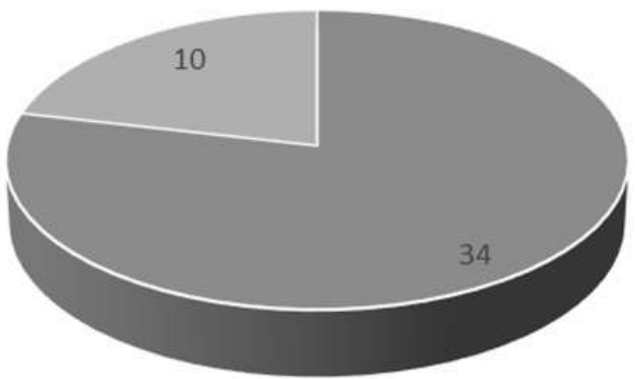

" Giai đoạn I = Giai đoạn II

Biểu đồ 3.1: Giai đoạn thiếu máu chi sau điều trị 1 thángthiếu máu chi sau điều trị 1 tháng 
Sau 1 tháng theo dõi và điều trị $\mathrm{ABI}$ có giảm ở chân $\mathrm{P}$ và chân $\mathrm{T}$ của các $\mathrm{BN}$ đi khám lại ở mức có ý nghĩa thống kê. Số liệu chung cả hai chân cho thấy có sự khác biệt ngay sau điều trị và khám lại sau 1 tháng.

Bảng 3.7:So sánh $A B I$ khi ra viện và khi khám lại sau 1 tháng.

\begin{tabular}{|l|l|c|c|l|}
\hline \multicolumn{2}{|l|}{ Thông số } & $\mathbf{N}$ & $\mathbf{A B I}$ & $\mathbf{p}$ \\
\hline \multirow{3}{*}{ Chân P } & Khi ra viện & \multirow{2}{*}{44} & $0,69 \pm 0,24$ & \multirow{2}{*}{$<\mathbf{0 , 0 5}$} \\
\cline { 2 - 2 } & Sau 1 tháng & & $0,67 \pm 0,24$ & \multirow{2}{*}{$<\mathbf{0 , 0 5}$} \\
\cline { 2 - 2 } Chân T & Khi ra viện & \multirow{2}{*}{42} & $0,67 \pm 0,26$ & \multirow{2}{*}{$<$} \\
\cline { 2 - 2 } & Sau 1 tháng & & $0,66 \pm 0,26$ \\
\hline \multirow{2}{*}{ Hai chân } & Khi ra viện & \multirow{2}{*}{86} & $0,68 \pm 0,25$ & \\
\cline { 2 - 2 } & Sau 1 tháng & & $0,67 \pm 0,25$ & \\
\hline
\end{tabular}

Có 2 BN hẹp tại stent ĐM chậu sau can thiệp mức độ nhẹ $(<50 \%)$ không cần xử trí

\section{Đánh giá sau 1 tháng}

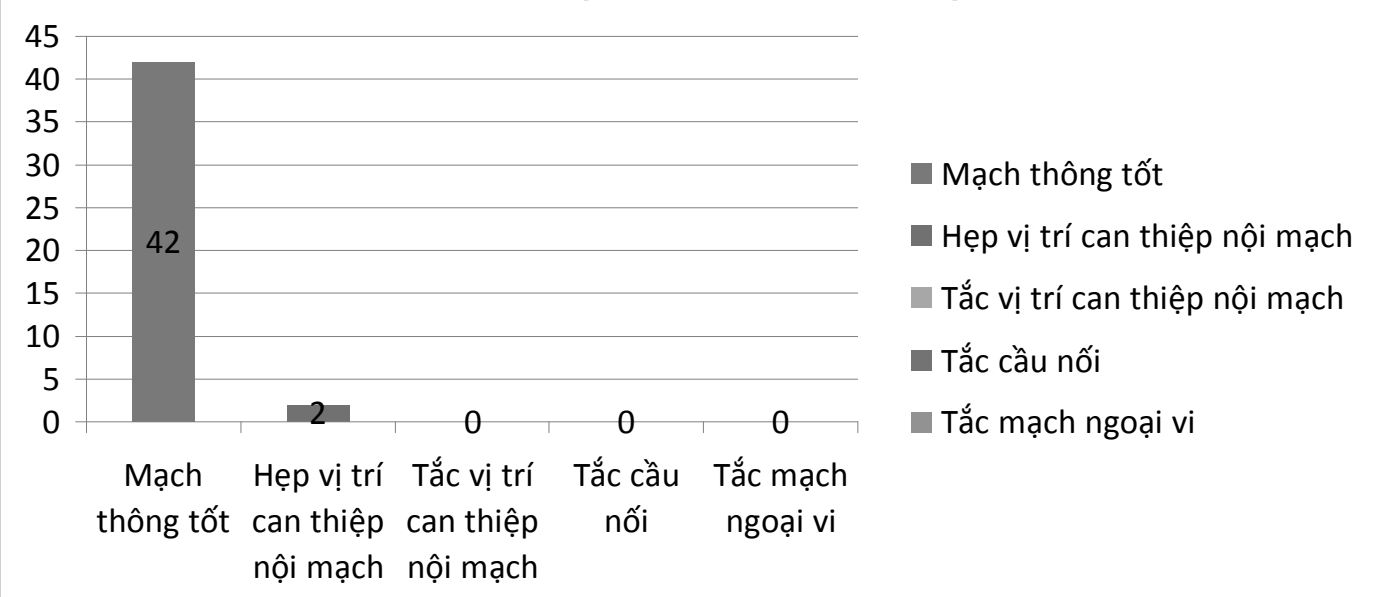

Biểu đồ 3.2: Siêu âm mạch máu sau 1 tháng $(n=44)$

\section{BÀN LUẬn}

4.1. Thời gian nằm viện trung bình là $17,42 \pm 8,33$ ngày. Thời gian nằm viện sau Hybrid trung bình là $11,96 \pm 5,78$, như vậy có khoảng gần 6 ngày để làm chẩn đoán và các thủ tục trước Hybrid cho $\mathrm{BN}$. Các $\mathrm{BN}$ của chúng tôi có đặc điểm là tuổi cao, nhiều bệnh lý phối hợp kèm theo nên các thăm dò trước mổ đều được tiến hành đầy đủ để đánh giá các nguy cơ cho điều trị cũng như cân nhắc biện pháp điều trị phù hợp nhất. Nằm viện lâu nhất là bệnh nhân sau bắc cầu ĐM chậu-ĐM đùi, nong bóng ĐM dưới gối trái ( $\mathrm{BN}$ số 30) biến chứng máu tụ sau phúc mạc. Bệnh nhân này được điều trị bảo tồn và kết quả khi ra viện tốt. 
Bảng 4.1: So sánh thời gian nằm viện sau Hybrid với tác giả khác

\begin{tabular}{|l|c|c|c|}
\hline \multicolumn{1}{|c|}{ Tác giả } & Năm công bố & Cỡ mẫu & $\begin{array}{c}\text { Thời gian nằm viện sau Hybrid } \\
\text { trung bình (ngày) }\end{array}$ \\
\hline Dosluoglu [4] & 2010 & 108 & $6,9 \pm 7,3$ \\
\hline Piazza M [6] & 2011 & 70 & 3,9 \\
\hline Min Zhou [8] & 2014 & 64 & $7,6 \pm 12$ \\
\hline Chúng tôi & 2019 & 52 & $11,96 \pm 5,78$ \\
\hline
\end{tabular}

Chúng tôi có thời gian nằm viện sau Hybrid cao hơn các tác giả khác, lý do cho thời gian nằm viện này là do đặc điểm của $\mathrm{BN}$ tới viện muộn. Mặc dù thành công về kỹ thuật cao (100\%) tuy nhiên việc xử trí các vấn đề có từ trước của BN như loét, hoại tử chi, teo cơ, giảm hoặc mất chức năng vận động do TBMN, nhiễm trùng mỏm cụt... là những lý do để thời gian điều trị kéo dài thêm.

Trong nghiên cứu này không có nhóm chứng để so sánh các $\mathrm{BN}$ được điều trị Hybrid này với $\mathrm{BN}$ được phẫu thuật, tuy nhiên Dosluoglu đã chứng minh thời gian nằm viện sau Hybrid thấp hơn so rõ rệt so với nhóm $\mathrm{BN}$ mổ mở (trung bình của Hybrid sau mổ là $6,9 \pm 7,3$ so với trung

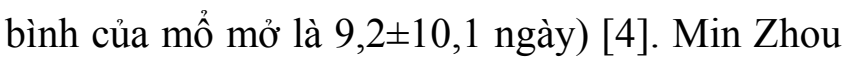
và cs thống kê các con số tương ứng là 7,6 412,0 và $15,5 \pm 17,3$ ngày $[8]$.
4.2.Hiệu quả giảm đau, liền vết thương và vết loét

Trong thiếu máu giai đoạn III: 90,0\% BN của chúng tôi hết đau sau mổ (bảng 3 ), số còn lại đỡ đau, không có $\mathrm{BN}$ nào phải cắt cụt. Với $\mathrm{BN}$ thiếu máu giai đoạn này nghĩa là chưa có vị trí loét và hoại tử, không có đường vào cho nhiễm trùng. Việc cải thiện tưới máu chi sẽ có hiệu quả ngay lập tức trong cải thiện triệu chứng lâm sàng.

Trong thiếu máu giai đoạn IV, tình trạng loét hoại tử chi chỉ cải thiện ở 64,28\% . Thực trạng các $\mathrm{BN}$ đến muộn, đã có loét/ hoại tử và tình trạng nhiễm trùng không cải thiện triệu chứng cho thấy ý nghĩa của việc chẩn đoán và điều trị $\mathrm{B} Đ \mathrm{MCD}$ ở các giai đoạn sớm hơn của bệnh. Các $\mathrm{BN}$ này sau đó đều cần cắt cụt từ cắt cụt nhỏ cho đến cắt cụt lớn.

\subsection{Cải thiện chỉ số áp lực cổ chân-cánh tay ABI}

Bảng 4.2: So sánh thay đổi ABI sau Hybrid với các tác giả khác

\begin{tabular}{|l|c|c|c|c|}
\hline \multicolumn{1}{|c|}{ Tác giả } & $\begin{array}{c}\text { Năm } \\
\text { công bố }\end{array}$ & Cõ̃ mấu & ABI trước điều trị & $\begin{array}{c}\text { ABI } \\
\text { sau điều trị }\end{array}$ \\
\hline Piazza M [6] & 2011 & 70 & \multicolumn{2}{|c|}{ Tăng 0.22 \pm 0.18} \\
\hline Argyriou C [7] & 2014 & 27 & $0,14 \pm 0,1$ & $0,69 \pm 0,28$ \\
\hline Dosluoglu [4] & 2010 & 108 & $0,35 \pm 0,25$ & $0,77 \pm 0,23$ \\
\hline Nishibe [5] & 2009 & 20 & $0,5 \pm 0,32$ & $0,79 \pm 0,24$ \\
\hline Antoniou [10] & 2009 & 60 & 0,34 & 0,72 \\
\hline Chúng tôi & 2019 & 52 & $0,36 \pm 0,23$ & $0,65 \pm 0,25$ \\
\hline
\end{tabular}


Sau điều trị chỉ số ABI tăng rõ rệt từ $0,36 \pm$ 0,23 lên mức $0,65 \pm 0,25$, khác biệt có ý nghĩa thống kê (bảng 5). Sự thay đổi này được ghi nhận ở cả hai chân của các BN.

Mức thay đổi $\mathrm{ABI}$ khác nhau giữa các tác giả, nguyên nhân là $\mathrm{BN}$ đầu vào của các tác giả khác nhau. Argyriou [7] lựa chọn các $\mathrm{BN}$ thiếu máu chi cấp tính trên nền mạch vữa xơ làm Hybrid, do có hiện tượng tắc cấp tính nên chỉ số $\mathrm{ABI}$ trước mổ là rất thấp.

Với $\mathrm{ABI}$ trước mổ tương đồng với nghiên cứu của chúng tôi, Nghiên cứu của Dosluoglu [4] và Antoniou [10] có sự thay đổi $\mathrm{ABI}$ lớn hơn chứng tỏ hiệu quả phục hồi lưu thông mạch máu là tốt hơn. Có thể đề cập đến một số nguyên nhân cho tình trạng này như các hạn chế về mặt sử dụng vật tư tiêu hao, kinh nghiệm của người làm phẫu thuật/can thiệp, tâm lý ngại can thiệp dưới gối và các khó khăn về kỹ thuật khi can thiệp mạch dưới gối. Đây là những yếu tố cần thiết phải cải thiện để tăng hiệu quả điều trị lưu thông mạch máu cho BN.

Khi so sánh thay đổi của $\mathrm{ABI}$ giữa các nhóm $\mathrm{BN}$ phẫu thuật mạch máu, can thiệp nội mạch và Hybrid, Dosluoglu [4] cũng nhận thấy có sự tăng ít hơn chỉ số $\mathrm{ABI}$ ở nhóm BN Hybrid so với hai nhóm còn lại, và căn nguyên là tổn thương mạch ở nhóm BN Hybrid có tính chất ngoại vi hơn: Nhóm mổ mở tăng từ $0,40 \pm 0,25$ lên $0,84 \pm 0,18$; nhóm can thiệp nội mạch tăng từ $0,50 \pm 0,22$ lên $0,86 \pm 0,18$ và nhóm Hybrid tăng từ $0,35 \pm 0,25$ lên $0,77 \pm 0.23$. Các $B N$ của chúng tôi có rất ít các can thiệp ngoại vi do chi phí, kinh nghiệm điều trị và yếu tố này cũng góp phần làm kết quả điều trị tăng tưới máu chưa so sánh được với các tác giả khác.

\subsection{Tình trạng nhiễm trùng cho chi thiếu máu giai đoạn IV}

Kummer và cộng sự nhận thấy trong thiếu máu chi trầm trọng, tỷ lệ cắt cụt nhỏ và cắt cụt lớn tăng đáng kể nếu có nhiễm trùng kể cả trong trường hợp phục hồi lưu thông mạch máu tốt [9]. Cả $3 \mathrm{BN}$ của chúng tôi bị cắt cụt/ sửa mỏm cụt đều có đặc điểm chung là có tình trạng nhiễm trùng rõ sau mổ và sau khi cắt cụt thì tình trạng này không còn.

Việc hạn chế nhiễm trùng sẽ giúp tỷ lệ bảo tồn chi cao hơn bằng các biện pháp: Tuyên truyền để phát hiện sớm bệnh từ giai đoạn đau cách hồi, sử dụng kháng sinh chống nhiễm khuẩn và chăm sóc vùng mổ tốt, theo dõi sớm tình trạng nhiễm trùng ở các $\mathrm{BN}$ có thiếu máu giai đoạn $\mathrm{IV}$ bằng lâm sàng và xét nghiệm để xử trí sớm.

\subsection{Cắt cụt sau Hybrid, thành công về bảo tồn chi}

Chỉ định cắt cụt ở các $\mathrm{BN}$ có thiếu máu giai đoạn IV là cần thiết trong trường hợp vùng hoại tử rộng, có hoại tử nhiễm trùng. Chúng tôi có $9 \mathrm{BN}$ phải cắt cụt trong đó $3 \mathrm{BN}$ là cắt cụt lớn. Việc không phải cắt cụt của nhóm $\mathrm{BN}$ thiếu máu giai đoạn IV cho thấy tác dụng của điều trị làm ngừng tiến triển của hoại tử chi. $\mathrm{BN}$ phải cắt cụt $1 / 3$ dưới cẳng chân là $\mathrm{BN}$ có hoại tử nhiễm trùng bàn chân. Nếu không phục hồi lưu thông mạch $\mathrm{BN}$ sẽ phải cắt cụt chi đến đùi. Như vậy Hybrid ngoài tác dụng giảm đau ở các bệnh nhân còn có tác dụng bảo tồn chi hiệu quả và giảm mức độ cắt cụt. Dosluoglu [4] trong nghiên cứu của mình cũng nhận thấy $\mathrm{BN}$ cắt cụt sớm sau mổ gắn liền với nhiễm trùng sâu và nhiễm trùng vật liệu nhân tạo.

\section{KẾT LUẬN}

Qua nghiên cứu $52 \mathrm{BN}$ có thiếu máu chi dưới mạn tính được điều trị bằng phối hợp phẫu thuật và can thiệp nội mạch, chúng tôi rút ra kết luận sau: Tỷ lệ tai biến và biễn chứng thấp không có tử vong. Các tai biến đều có thể kiểm soát được hoàn toàn trong quá trình điều trị. Hiệu quả cải thiện tưới máu chi cao: $\mathrm{ABI}$ tăng rõ rệt từ 
$0,36 \pm 0,23$ lên $0,65 \pm 0,25$ ( $\mathrm{p}<0,05)$. Chi được bảo tồn chiếm $98,03 \%$.Phương pháp phẫu thuật kết hợp can thiệp nội mạch là phương pháp điều trị có giá trị tốt cho những bệnh nhân có bệnh tắc động mạch mạn tính chi dưới, có hiệu quả đáng kể khi cải thiện các triệu chứng lâm sàng, cận lâm sàng ở thời điểm sớm.

\section{TÀI LIỆU THAM KHẢO}

1. Đoàn Quốc Hưng (2011). Can thiệp nội mạch và phối hợp phẫu thuật mổ mở- Can thiệp nội mạch: xu hướng mới trong điều trị bệnh mạch máu. Tạp chí nghiên cúu y học, 80, 354, 64-60.

2. Đoàn Quốc Hưng, Nguyễn Duy Thắng, Nguyễn Hữu Ước và cộng sự (2014). Điều trị bệnh mạch máu phức tạp bằng can thiệp nội mạch phối hợp phẫu thuật (Hybrid). Tạp chi tim mach hoc Việt Nam, 65, 34-41.

3. Phạm Minh Ánh, Lê Đức Tín, Trương Thế Hiệp và cộng sự (2014). Đánh giá kết quả phẫu thuật kết hợp can thiệp nội mạch trong điều trị tắc động mạch mạn tính chi dưới. Nghiên cúu Y học Y Hoc TP. Hồ Chí Minh, 18(2), 223-228.

4. Dosluoglu HH, Lall P, Cherr GS et al (2010). Role of simple and complex Hybrid revascularization procedures for symptomatic lower extremity occlusive disease. $J$ Vasc Surg, 51, 1425-1435 e1421.

5. Nishibe T, Kondo Y, Dardik A et al (2009). Hybrid surgical and endovascular therapy in multifocal peripheral TASC D lesions: up to three-year follow-up. J Cardiovasc Surg (Torino), 50, 493- 499.
6. Piazza M, Ricotta JJ , Bower TC, Kalra M, Duncan AA, Cha S, Gloviczki P (2011). Iliac artery stenting combined with open femoral endarterectomy is as effective as open surgical reconstruction for severe iliac and common femoral occlusive disease. J Vasc Surg. Aug; 54(2): 402-11.

7. Argyriou C, Georgakarakos E, Georgiadis GS, Antoniou GA, Schoretsanitis N, Lazarides M. (2014). Hybrid revascularization procedures in acute limb ischemia. Ann Vasc Surg. Aug;28(6):1456-62.

8. Min Zhou, Dian Huang, Chen Liu, Zhao Liu, Min Zhang, Tong Qiao, and Chang-Jian Liu. (2014) Comparison of Hybrid procedure and open surgical revascularization for multilevel infrainguinal arterial occlusive disease. Clin Interv Aging. 2014; 9: 1595-1603.

9. Kummer O, Widmer MK, Plüss S, Willenberg T, Vögele J, Mahler F, Baumgartner I. Does infection affect amputation rate in chronic critical leg ischemia? Vasa. 2003 Feb;32(1):18-21.

10. G.A.Antoniou, Sfyroeras GS, Karathanos C et al (2009). Hybrid Endovascular and Open Treatment of Severe Multilevel Lower Extremity Arterial Disease. European Journal of Vascular and Endovascular Surgery Volume 38, Issue 5, November, Pages 616-622. 